\title{
Connecting Theory and Practice:
}

\section{cais acsi}

\section{Implications of Coherence Theory in the Fight Against Fake News}

Mike Chee, MLIS, MEd, MA

University of Waterloo

\section{Fake News is Political}

Misinformation online is a prominent concern, framed as an opportunity and responsibility for the LIS community. While, as Sullivan (2018) puts it, the "primary concern about misinformation among LIS authors has been the fact that it is out there" (p. 2), it is useful to ask bluntly why we should care.

Sullivan ultimately presents that this misguidance is problematic because it has ramifications for politics in our democratic system, reasoning echoed by many others (for example, Waldrop, 2017; Cerase \& Santoro, 2018). The main

issue with viral misinformation thus seems to be for its potential to upset political environments.

\section{Case Study: Australian Bush Fires}

The Australian bush fires started in September of 2019, were under control by February of 2020, and were over by early March of 2020 (Machemer, 2020). They were already one of the most severe on record by early January (Irfan, 2020a), and have an inextricable tie to climate change in the political arena (Crowther, 2020). Since early into the fire season, climate change was attributed as a factor in the severity of the fires, according to scientists (Irfan, 2020a). At the beginning of January, a flurry of activity took off on social media, especially on Twitter, using the hashtag \#ArsonEmergency and pointing to the "fact" that most of the existing bushfires had been set by arsonists (Irfan, 2020b). This situation must thus be understood as inherently political, tied to a position on the reality and severity of climate change.

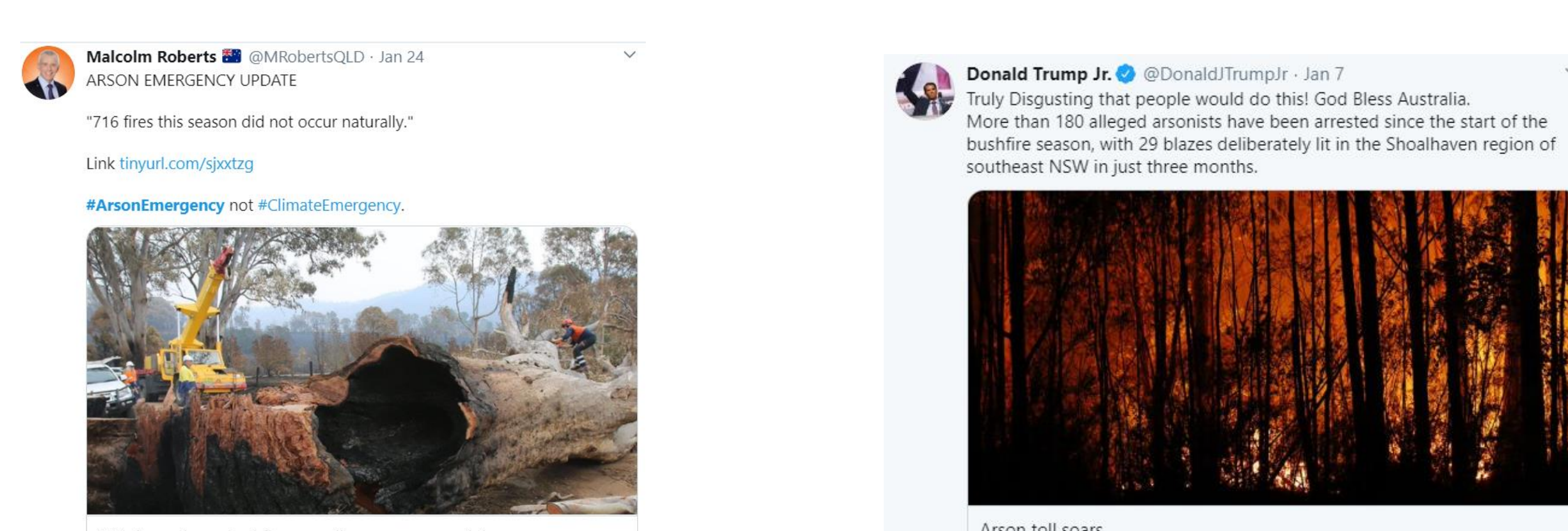

\section{Uncertain Resolution of the Case}

The hashtag \#ArsonEmergency continues to be invoked on Twitter, especially in relation to the new bush fires in the United States. Although many articles have been written debunking

the arson theory (e.g. Irfan, 2020b; Chappell, 2020; The Guardian, 2020; Reality Check Team, 2020; Nguyen \& Bogel, 2020), many still propagate it as fact. In the context of the fight against Fake News, as long as there are people who don't thin

something has been resolved, opportunity exists for the propagation of another "truth." Resolution needs to be considered holistically, not on the basis of particular, though expansive, echo chambers.
Coherence Theory

The Coherence theory of truth sees truth as that which coheres with <blank $>$, with <blank> serving as a stand-in for various authorities: whether "beliefs of the majority" "beliefs of intellectuals", or "beliefs of myself". The key element of this theory is that coherence must have logical consistency. Postmodernist Coherence theory goes a step further, replacing $<$ blank> with "beliefs of influential people", and seeing no difference between "acceptance of truth" from "is truth". In the case of science, "truth" is constructed through the coherence of "influential people" (scientists), with the logical consistency that experiments can be replicated. While "truth" in science can theoretically be tested, "truth" in more qualitative spheres like politics is dictated entirely by coherence, where $<$ blank $>$ is "political figures". The key element of logical consistency becomes difficult to determine and those seeking "truth"

cannot stop at the most convenient coherence.
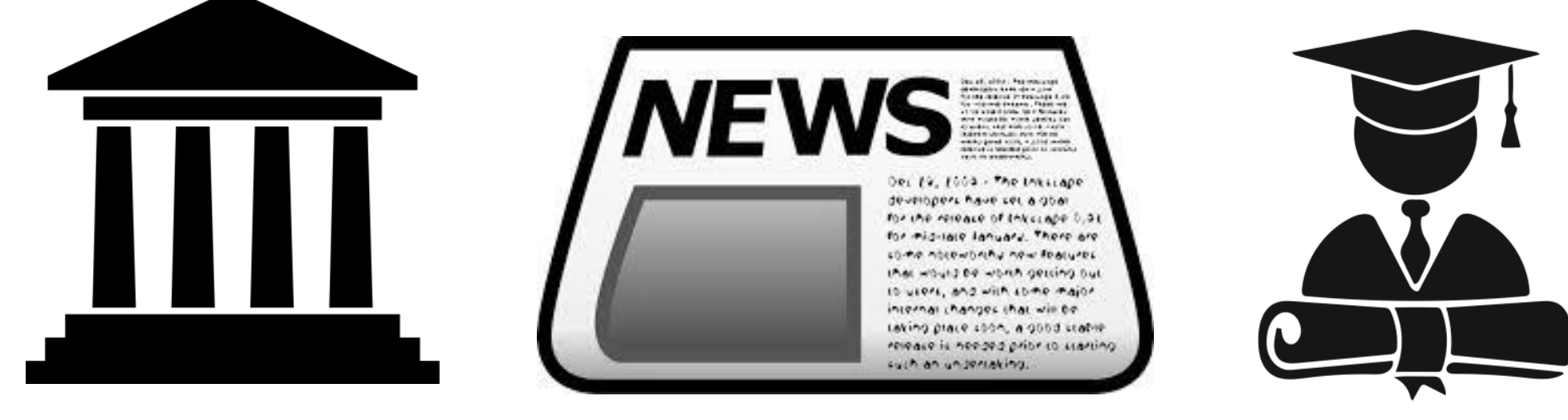

Pre-internet, traditional authorities relayed "truth".

\section{Coherence Online}

The online environment has dramatically shifted the traditional loci of "influential people". Foucault (1977) describes that

"truth" "is produced and transmitted under the control, dominant if not exclusive, of a few great political and economic apparatuses (university, army, writing, media...)" (p. 13). While still accurate to some degree, this description emphasizes a new paradigm evident within the online context: the establishment of who and what constitutes "influential people" is currently ongoing, largely on social media platforms. Diverse actors in this evolving context are stepping forward into the "influential people" void and dividing coherence. For example, when footage purporting to show some newsworthy event surfaces online, it remains at the discretion of consumers to decide if the author is an "influential person" on this matter

(Rose, 2020). This example highlights the tension at play seeking "truth" on the internet: everyone can have a voice, but in a Coherence theory of truth model, only a few voices will be influential enough to create "truth".

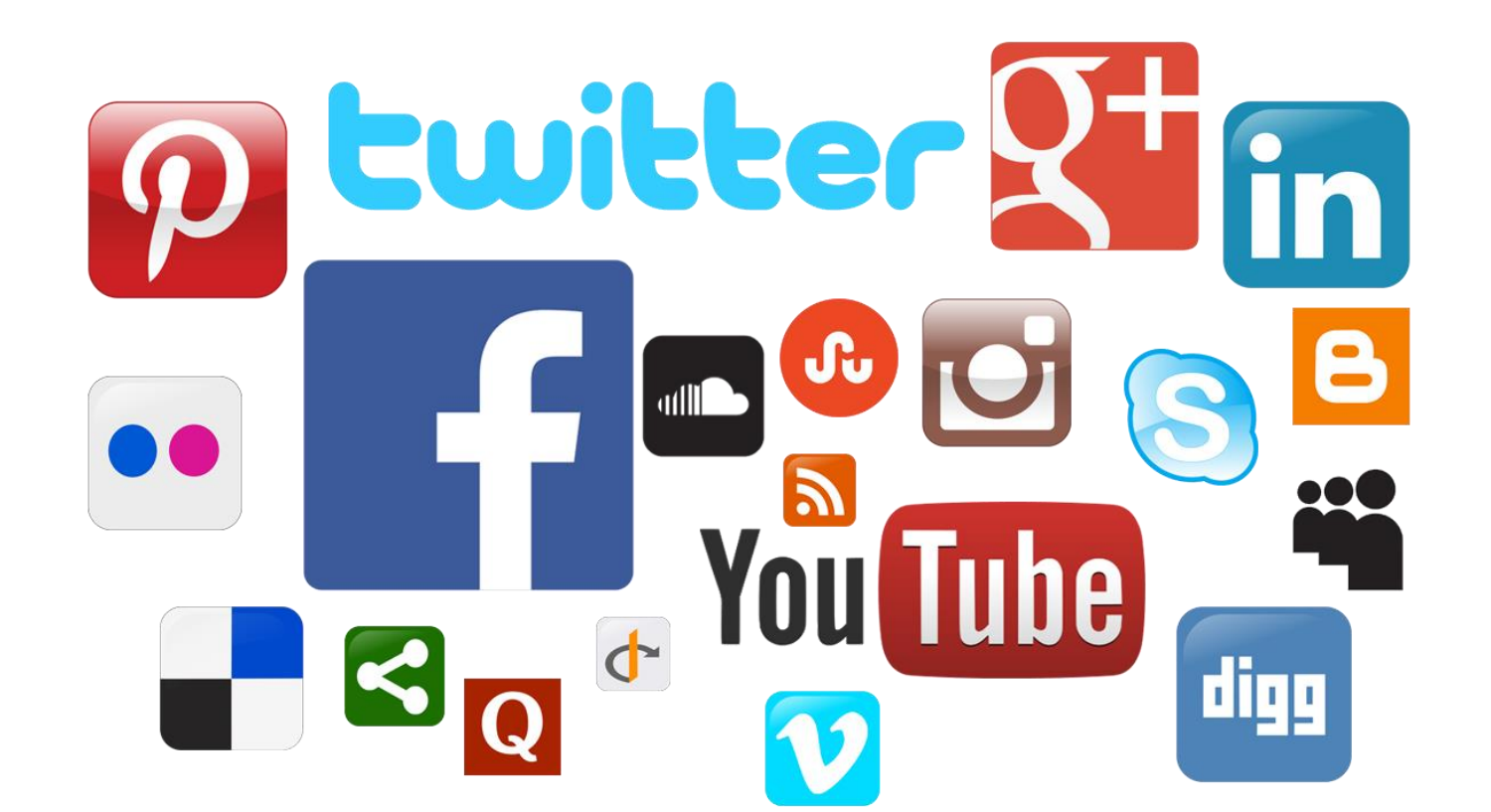

With the internet, the loudest voices can relay "truth".
Fragmented Coherence

As Sullivan (2018) makes clear, when "correct" information is presented to people holding misconceptions who then change their mind, they are susceptible to revert to their previous (incorrect) view after a time. I would posit that this may relate to a fragmented coherence, since the person remembers the original source as an "influential person". Since the baseline for who forms "truth" is no more rigorous than a need to be "influential", non-traditional sources of "truth", such as socia media influencers, are gaining prominence. Combatting influential misinformation in a neutral way is fraught, since as Sullivan warns, the backfire effect can lead people presented with balanced pro/con arguments to choose the "wrong" one. In the face of the backfire effect, and as the struggle around who is an "influential person" rages, the best way to win is to present only one option for the "truth".

\section{A Role for LIS Professionals}

If misinformation on the internet stems from a fragmented coherence, a straightforward solution would see more coherence formed. LIS professionals have a role to play as information filters, offering professional recommendations on what is true based on logical consistency. We can only play a role, however, if we commit to taking a stand and taking a side. There is a pervasive commitment in the LIS profession to a principle of neutrality, though as Johnson (2016) argues well, neutrality is actually a political position that tacitly endorses the status quo. If we truly want to make an impact, we must abandon the outdated myth of neutrality and come out solidly in support of the voices, and thus "truths", we want to amplify.

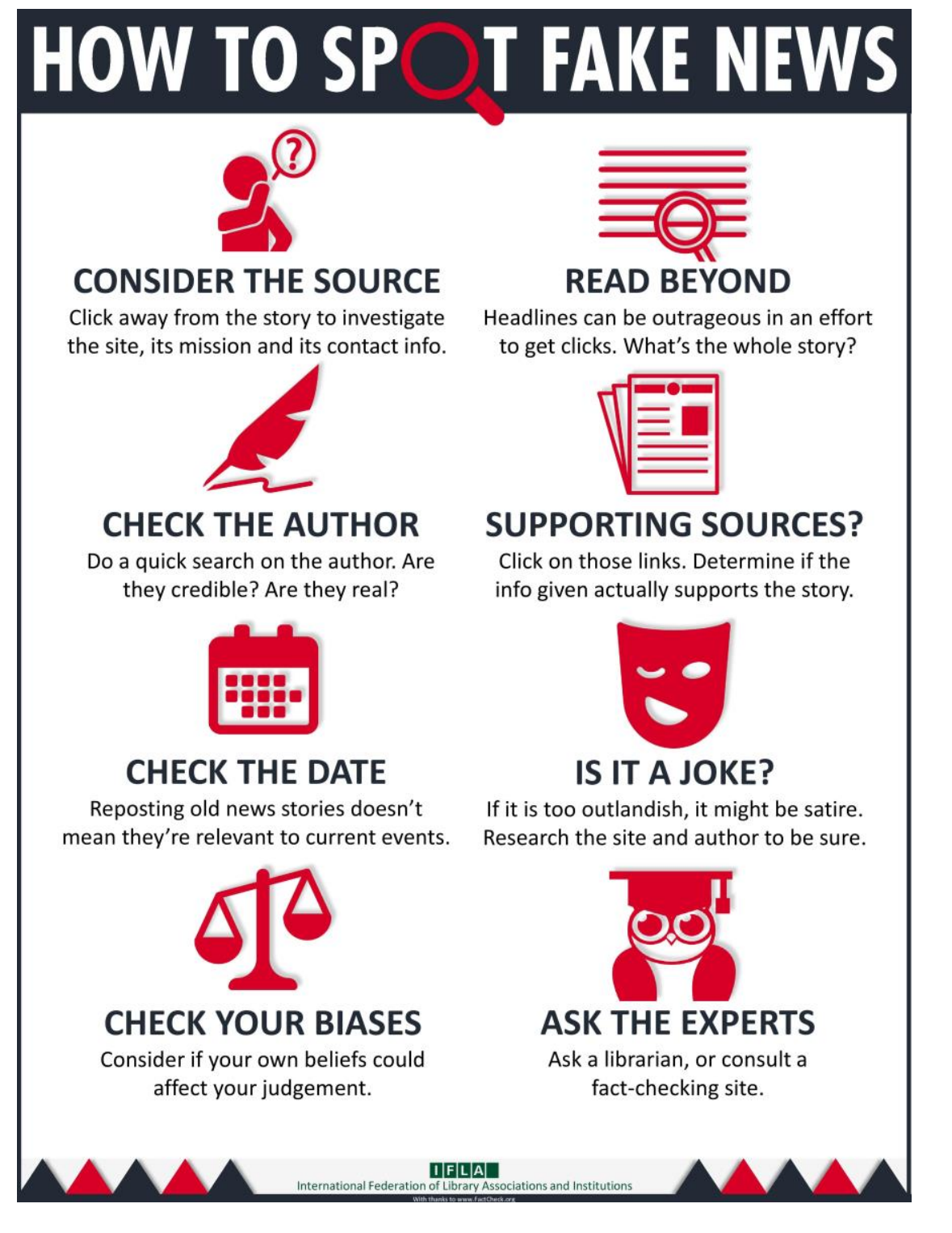

Excellent work, like this tip sheet on spotting Fake News from IFLA, is already being undertaken by LIS professionals. However, these tips largely put the onus on consumers and their ability to determine logical consistency. Looking to how coherence is formed may provide another way forward in the fight against Fake News.

\section{Future Work}

Conceptualizing the issue of Fake News as related to a fragmented coherence may help future research on solutions to fake news, providing a different way of approaching the problem. This idea could be used to develop and test a tool to combat fake news based on how people form truth through coherence. 